\title{
Osteoartritli Hastaların Evde Egzersiz Yapma ve Yarar Görme Durumları
}

\section{Benefits of Home-Based Exercising Ability in Patients With Osteoarthritis}

\author{
Nazan KILIÇ AKÇA, Aydan DOĞAN
}

Bozok Üniversitesi Sağlık Yüksek Okulu, Yozgat, Türkiye

\section{Özet}

Amaç: Bu çalışma osteoartrit $(\mathrm{OA})^{\prime}$ li hastaların evde egzersiz yapma ve egzersizden yarar görme durumlarını belirlemek amacıyla tanımlayıcı olarak yapıldı.

Gereç ve Yöntem: Çalışma Fizik Tedavi ve Rehabilitasyon (FTR) polikliniğine başvuran, OA tanısı konulan, kurum izni alınan ve çalışmaya katılmayı kabul eden 103 hasta ile tamamlandı. Araştırmanın verileri literatür taranarak oluşturulan anket formuyla FTR polikliniğindeki hastalarla yüz yüze görüşme tekniği kullanılarak yapıldı. Verilerin değerlendirilmesinde ki-kare önemlilik testi ve lojistik regresyon analizi kullanıldı. $p<0,05$ değeri istatistiksel olarak anlamlı kabul edildi.

Bulgular: Katılımcıların \%58,3'ünün egzersiz yaptığı ve egzersiz yapanların $\% 80^{\prime}$ inin haftada üç defa kas germe ve eklem egzersizleri yaptıkları saptandı. Egzersiz yapanların \%66,7'si yaptığı egzersizin OA'ya bağlı ağrı, sabah tutukluğu vb. şikayetlerini azalttığını belirtti. Hastaların en fazla ağrı $(\% 77,6)$ olmak üzere, egzersizin etkinliğine inanmama, zaman bulamama, yeterince bilgisinin olmaması gibi nedenlerle düzenli egzersiz yapmadıkları belirlendi. $\mathrm{OA}^{\prime} ı$ ' hastaların egzersiz yapmasına bilgi alma durumunun çok ileri düzeyde $(p<0,001)$, tutulan eklem türü ve gelir durumunun anlamlı düzeyde $(p<0,01)$ etkisi olduğu bulundu.

Sonuç: $\mathrm{OA}^{\prime}$ ı hastaların yarıdan fazlasının evde çeşitli egzersizler yaptıkları ve yapılan egzersizin hastalığa bağlı yaşanan semptomları azalttığı saptandı. Türk Fiz Tıp Rehab Derg 2012;58:288-93.

Anahtar Kelimeler: Osteoartrit; ev egzersiz programı

\section{Summary}

Objective: This study was conducted to determine the ability of osteoarthritis (OA) patients to exercise at home and the extent to which they benefit from such exercise.

Metarials and Methods: The research was carried out on 103 patients who had been admitted to the physical therapy and rehabilitation (PMR) clinic with the diagnosis of $\mathrm{OA}$, and who agreed to participate in the study, having been granted permission by the institution. The research data were obtained using a questionnaire, formulated on the basis of a literature review, which was completed by patients at the PMR clinic, using a face-to-face interview technique. In the assessment of data, the chi square test and logistic regression analysis were used. $p$ value less than 0.05 was considered statistically significant. Results: It was found that $58.3 \%$ of participants exercised at home, and that $80 \%$ of those who exercised did muscle and joint exercises three times a week. Sixty-six point seven percent of those who exercised stated that exercise reduced symptoms such as pain, morning stiffness caused by $O A$. It was established that the reasons for patients not taking regular exercise included principally pain ( $76 \%$ of them), disbelief in the efficacy of exercise, lack of time and information. The study showed that availability of information $(p<0.001)$ was a highly statistically significant factor in determining whether patients do exercise at home, and that affected joint type and level of income $(p<0.01)$ are also statistically significant factors.

Conclusion: The results of our study indicated that more than half of the OA patients made different kinds of exercise at home and that these exercises reduced their symptoms. Turk J Phys Med Rehab 2012;58:288-93.

Key Words: Osteoarthritis; home-based exercise

Yazışma Adresi/Address for Correspondence: Dr. Nazan Kilıç Akça, Bozok Üniversitesi Sağlık Yüksek Okulu, Yozgat, Türkiye 


\section{Giriş}

Osteoartrit (OA) eklemlerin en sık görülen hastalığı olup tüm Dünya'da ve Türkiye'de önemli bir sağlık sorunudur. OA sinsi başlar ve yıllar içinde yavaşça ilerler. Dünyada 30 yaş üzeri kadınların \%7-8'ine, erkeklerin \%5-6'sına OA tanısı konmakta ve yaş ilerledikçe bu oran artmaktadır (1). Illerleyen yaş ile birlikte toplumsal sağlık taramalarında OA'nın önemli bir sağlık sorunu ve uzun süreli özürlülük nedeni olduğu görülmektedir $(2,3)$.

Bugün için OA'nın kesin bir tedavisi bulunmamaktadır, bu nedenle tedavi sıklıkla ağrı, tutukluk ve hareket kısıtlılı̆ı gibi semptomların kontrolüne odaklanmıştır $(1,4)$. Yapılan çalışmalarda $\mathrm{OA}^{\prime}$ Iı hastalarda evde yapılan orta düzeyde egzersizin ağrı, hareket kısıtlılı̆ı, işlevsel kayıp, sabah tutukluğu, emosyonel bozukluklar ve depresyon gibi fiziksel ve psikolojik semptomların kontrolünde etkin bir öğe olduğu belirtilmektedir (1,5-9).

OA kronik ve çok yönlü kayıplara neden olan bir eklem hastalığıdır. Bu yüzden tedavisi de multidisipliner ekip içerisinde planlanarak sürdürülmelidir. OA tedavisi bireye özgü olmalı ve tedavi sürecine bireyin de aktif katılımı sağlanmalıdır. Kronik bir hastalık olan $O A^{\prime}$ nın tedavi ve bakım süreci hastayla yapılandırımalı ve hastanın egzersiz öz yeterliliği sağlanmalıdır (1,8-9).

$\mathrm{Bu}$ çalışma, OA'lı hastaların evde egzersiz yapma ve egzersizden yarar görme durumlarını belirlemek amacıyla tanımlayıcı olarak yapılmıştır.

\section{Gereç ve Yöntemler}

Araştırma il merkezinde bulunan bir hastanenin Fizik Tedavi ve Rehabilitasyon (FTR) polikliniğine başvuran hastalar ile yapıldı. Çalışmaya, FTR polikliniğine muayeneye gelen ve daha önce Amerikan Romatoloji Koleji Osteoartrit tanı kriterlerine göre diz, kalça eklemi ve servikal omurgada OA tanısı konulmuş, en az bir yıldır tedavi gören 131 hasta dahil edildi. Ancak 28 hasta çalışmaya katılmak istemediği için 103 hasta ile çalışma tamamlandı.

Araştırmacılar tarafından konuya ilişkin literatür taranarak (1-6) hazırlanan anket formunun birinci bölümünde hastaların sosyodemografik özelliklerini (11 soru) ve hastalık özelliklerini (3 soru), ikinci bölümde ise egzersiz yapma özelliklerini (8 soru) içeren sorular yer almaktadır.

Araştırma yapılan kurumdan araştırma öncesi yazılı izin ve çalışmaya katılan hastalardan da araştırmanın amacı açıklanarak sözel izin alındı. Hastalara müdahale yapılmadığından ve bulunduğumuz ilde etik kurul komisyonu olmadığı için etik kurul izni alınmadı. Anket uygulaması FTR polikliniğinde hastalarla yüz yüze görüşme tekniği kullanılarak uygulandı ve her bir anketin doldurulması ortalama 7-10 dakika sürdü.

Egzersizden yarar sağlama kriteri olarak hastaların kendi ifadeleri (ağrı, kilitlenme, hareket kısıtlılığı ve yorgunluk vb semptomlarda azalma) kabul edildi (8,9-11).

Araştırmadan elde edilen verilerin değerlendirilmesinde yüzde, ki-kare testi ve lojistik regresyon analizi kullanıldı. OA'sı olan bireylerin egzersiz yapma durumunu etkilediği belirlenen beş değişkenin etkisi lojistik regresyon analizi ile değerlendirildi.
Bağımlı değişken olarak egzersiz yapma durumu, yordayan (etkileyen) değişken olarak yaş, eğitim, gelir, tutulan eklem türü, bilgi alma durumu enter metodu ile modele alınarak analiz yapıldı. Sonuçlar $p<0,05$ için istatistiksel olarak anlamlı kabul edildi.

\section{Bulgular}

Hastaların \%39,8'i 45-59 yaş grubunda, \%72,8'i kadın ve \%42,7'si ilköğretim mezunudur. Hastaların \%82,5'inin evli, \%65'inin çalıştığı, \%63,1'inin şehir merkezinde yaşamakta ve $\% 66$ 'sının ekonomik durumunun orta düzeyde olduğu

\section{Tablo 1. Hastaların egzersiz yapma özelliklerinin dağılımı.}

\begin{tabular}{|c|c|}
\hline Egzersiz yapma özellikleri & n (\%) \\
\hline \multicolumn{2}{|l|}{ Egzersiz yapma durumu $(n=103)$} \\
\hline Yapan & $60(58,3)$ \\
\hline Yapmayan & $43(41,7)$ \\
\hline \multicolumn{2}{|l|}{ Egzersiz yapma sıklığı $(n=60)$} \\
\hline Haftada 1-2 kez & $13(20,0)$ \\
\hline Haftada 3 ve üzeri & $47(80,0)$ \\
\hline \multicolumn{2}{|l|}{ Egzersiz türü * $(n=60)$} \\
\hline Kas güçlendirme egzersizleri & $51(54,9)$ \\
\hline Eklem hareket açıklığı egzersizleri & $43(48,5)$ \\
\hline Yürüme & $33(32,5)$ \\
\hline Koşma & $12(7,8)$ \\
\hline \multicolumn{2}{|l|}{ Egzersizden yarar sağlama $(n=60)$} \\
\hline Sağlayan & $40(66,7)$ \\
\hline Sağlamayan & $20(33,3)$ \\
\hline \multicolumn{2}{|c|}{ Egzersiz sırasında rahatsızlık yaşama $(n=60)$} \\
\hline Yaşayan & $48(80,0)$ \\
\hline Yaşamayan & $12(20,0)$ \\
\hline \multicolumn{2}{|c|}{ Egzersiz sırasında en yoğun yaşanan şikayet $(n=60)$} \\
\hline Ağrı & $37(77,1)$ \\
\hline Kilitlenme & $6(22,5)$ \\
\hline Yorgunluk & $5(10,4)$ \\
\hline \multicolumn{2}{|c|}{ Düzenli egzersiz konusunda bilgilendirilme durumu $(n=103)$} \\
\hline Bilgilendirilen & $47(45,6)$ \\
\hline Bilgilendirilmeyen & $56(54,4)$ \\
\hline \multicolumn{2}{|c|}{ Düzenli egzersiz konusunda bilgi alınan kişi $(n=47)$} \\
\hline Hemşire & $24(51,1)$ \\
\hline Hekim & $16(34,0)$ \\
\hline Fizyoterapist & $7(14,9)$ \\
\hline \multicolumn{2}{|c|}{ Almıs olduğu bilgiyi yeterli bulma ( $n=47)$} \\
\hline Yeterli & $11(23,4)$ \\
\hline Yetersiz & $36(76,6)$ \\
\hline \multicolumn{2}{|l|}{ Egzersiz yapmama nedenleri* $(n=43)$} \\
\hline Ağrı & $33(77,6)$ \\
\hline Etkinliğine inanmama & $6(14,5)$ \\
\hline Zaman bulamama & $5(11,6)$ \\
\hline Bilgisizlik & $3(7,7)$ \\
\hline Yalnızlık & $2(5,8)$ \\
\hline
\end{tabular}


yürüyüş $(\% 32,5)$ yaptıkları saptanmıştır. Egzersiz yapan hastaların yarıdan fazlası $(\% 66,7)$, egzersizin hastalığa bağlı yaşadığı ağrı, kilitlenme ve hareket kısıtlığı gibi şikayetlerini azalttığını ifade etmiştir. Hastaların evde egzersiz yaparken ise ağrı $(\% 77,1)$, kilitlenme $(\% 22,5)$ gibi rahatsızlıklar yaşadığı belirlenmiştir (Tablo 1). Hastaların \%45,6'sının daha önce OA'da egzersizin faydaları konusunda bilgilendirildikleri ve bu bilgilendirmenin ise hemşire $(\% 51,4)$, hekim $(\% 34)$ ve fizyoterapist $(\% 14,9)$ tarafından yapıldığı saptanmıştır. Yaptığımız bu çalışmada hastaların yarıdan fazlası $(\% 76,6)$ egzersiz yapmaları için verilen bilginin yeterli olmadığını belirtmiş̧ir. OA'lı hastaların en fazla ağrı olmak üzere, egzersizin etkinliğine inanmama, zaman bulamama, yeterince bilgisinin olmaması ve yalnızlık gibi nedenlerle düzenli egzersiz yapmadıkları saptanmıştır (Tablo 1 ).

Eğitim düzeyi arttıkça egzersiz yapma ve egzersizden yarar görme oranının arttığı, 45-59 yaş grubunun diğer yaş gruplarına göre daha fazla egzersiz yaptığı, 30-44 yaş grubunun ise egzersizden daha fazla yarar gördüğü saptanmıştır $(p<0,05)$. Orta gelir düzeyine sahip kişilerin diğer gelir gruplarına göre daha fazla

Tablo 2. Hastaların bazı özelliklerine göre egzersiz yapma durumlarının dağılımı ( $n=103)$

\begin{tabular}{|c|c|c|c|c|}
\hline \multirow[t]{2}{*}{ Özellikler } & \multicolumn{2}{|c|}{ Egzersiz yapma durumu } & \multicolumn{2}{|l|}{ Test } \\
\hline & Yapan n (\%) & Yapmayan n (\%) & $\chi^{2}$ & $p$ \\
\hline \multicolumn{5}{|l|}{ Cinsiyet } \\
\hline Kadın & $43(57,3)$ & $32(42,7)$ & 0,096 & 0,757 \\
\hline Erkek & $17(60,7)$ & $11(39,3)$ & & \\
\hline \multicolumn{5}{|l|}{ Yaş grubu } \\
\hline 30-44 yaş & $25(64,1)$ & $14(35,9)$ & & \\
\hline 45-59 yaş & $28(68,3)$ & $13(31,7)$ & 9,567 & 0,008 \\
\hline 60 yaş ve üzeri & $7(30,4)$ & $16(69,6)$ & & \\
\hline \multicolumn{5}{|l|}{ Eğitim durumu } \\
\hline Okuryazar olmayan & $9(37,5)$ & $15(62,5)$ & & \\
\hline İlköğretim & $25(56,8)$ & $19(43,2)$ & 7,987 & 0,018 \\
\hline Lise ve üzeri & $26(74,3)$ & $9(25,7)$ & & \\
\hline \multicolumn{5}{|l|}{ Aktif çalışma durumu } \\
\hline Çalışan & $25(69,4)$ & $11(30,6)$ & 2,851 & 0,091 \\
\hline Çalışmayan & $35(52,2)$ & $32(47,8)$ & & \\
\hline \multicolumn{5}{|l|}{ Gelir durumu } \\
\hline Iyi & $12(60,0)$ & $8(40,0)$ & & \\
\hline Orta & $45(66,2)$ & $23(33,8)$ & 10,806 & 0,005 \\
\hline Kötü & $3(20,0)$ & $12(80,0)$ & & \\
\hline \multicolumn{5}{|l|}{ Etkilenen eklem sayısı } \\
\hline 1 & $12(48,0)$ & $13(52,0)$ & & \\
\hline 2 & $35(70,0)$ & $15(30,0)$ & 5,528 & 0,063 \\
\hline 3 ve üzeri & $13(46,4)$ & $15(53,6)$ & & \\
\hline \multicolumn{5}{|l|}{ Tutulan eklem türü } \\
\hline Diz eklemi & $21(55,3)$ & $17(44,7)$ & & \\
\hline Kalça eklemi & $11(37,9)$ & $18(62,1)$ & 10,708 & 0,005 \\
\hline Servikal omurga & $8(77,8)$ & $8(22,2)$ & & \\
\hline \multicolumn{5}{|c|}{ Egzersiz konusunda bilgilendirilme durumu } \\
\hline Bilgilendirilen & $37(78,7)$ & $10(21,3)$ & 14,896 & 0,000 \\
\hline Bilgilendirilmeyen & $23(41,1)$ & $33(58,9)$ & & \\
\hline \multicolumn{5}{|c|}{ Bilgilendirmeyi yapan sağlık personeli $(n=47)$} \\
\hline Hemşire & $24(100,0)$ & $0(0,0)$ & & \\
\hline Hekim & $8(50,0)$ & $8(50,0)$ & 1,638 & 0,009 \\
\hline Fizyoterapist & $5(71,4)$ & $2(28,6)$ & & \\
\hline
\end{tabular}


Eğitim düzeyi arttıkça egzersiz yapma ve egzersizden yarar görme oranının arttı̆̆ı, 45-59 yaş grubunun diğer yaş gruplarına göre daha fazla egzersiz yaptığı, 30-44 yaş grubunun ise egzersizden daha fazla yarar gördüğü saptanmıştır $(p<0,05)$. Orta gelir düzeyine sahip kişilerin diğer gelir gruplarına göre daha fazla egzersiz yaptığı ve egzersizden daha fazla yarar gördüğü belirlenmiş̧ir $(p<0,05$, Tablo 2,3$)$. Hastaların eklem türüne göre egzersiz yapma durumlarına bakıldığında servikal omurgası tutulan hastaların diz ve kalça eklemi tutulan hastalara göre daha fazla egzersiz yaptığı bulunmuştur $(p<0,05)$. OA'ya bağlı semptomları kontrol etmede egzersizin önemi konusunda bilgilendirilenlerin bilgilendirilmeyenlere göre, egzersizin önemi ve yapma konusunda hemşireden bilgi alan hastaların da diğer sağılık personellerinden bilgi alanlara göre daha fazla egzersiz yaptığı saptanmıştır $(p<0,05$, Tablo 2). Çalışanların çalışmayanlara göre ve haftada bir-iki kez egzersiz yapanların haftada 3 ve daha fazla egzersiz yapanlara göre egzersizden daha fazla yarar gördüğü ve aradaki farkın istatistiksel olarak anlamlı olduğu belirlenmiştir $(p<0,05$, Tablo 3$)$.

OA'sı olan hastaların bazı özelliklerinin egzersiz yapma durumuna etkisi lojistik regresyonla değerlendirildiğinde, egzersiz yapma konusunda bilgi alan hastaların egzersiz yapma olasılığının eğitim almayanlara göre 7,96 kat $(p<0,001)$, servikal omurgası tutulan hastaların egzersiz yapma olasiığının diz ve kalça eklemi tutulanlara göre 7,87 kat $(p<0,01)$, gelir durumu iyi ve orta olan hastaların egzersiz yapma olasilığını kötü olanlara göre $20,98(p<0,01)$ kat daha fazla olduğu saptanmıştır. Eğitim ve yaș özelliğinin egzersiz yapmaya etkisinin olmadığı belirlenmiştir (Tablo 4).

Tablo 3. Hastaların bazı özelliklerine göre egzersizden yarar görme durumlarının dağlımı $(n=60)$.

\begin{tabular}{|c|c|c|c|c|}
\hline \multirow[t]{2}{*}{ Özellikler } & \multicolumn{2}{|c|}{ Yarar görme durumu } & \multicolumn{2}{|l|}{ Test } \\
\hline & Gören n (\%) & Görmeyen n (\%) & $x^{2}$ & $p$ \\
\hline \multicolumn{5}{|l|}{ Yaş grubu } \\
\hline 30-44 yaş & $18(78,3)$ & $5(21,7)$ & & \\
\hline 45- 59 yaş & $19(70,4)$ & $8(29,6)$ & 7,608 & 0,022 \\
\hline 60 yaş ve üzeri & $3(30,0)$ & $7(70,0)$ & & \\
\hline \multicolumn{5}{|l|}{ Eğitim durumu } \\
\hline Okuryazar olmayan & $5(41,7)$ & $7(58,3)$ & & \\
\hline İlköğretim & $12(54,5)$ & $10(45,5)$ & 10,378 & 0,006 \\
\hline Lise ve üzeri & $23(88,5)$ & $3(11,5)$ & & \\
\hline \multicolumn{5}{|l|}{ Çalışma durumu } \\
\hline Çalışan & $21(87,5)$ & $3(12,5)$ & 7,813 & 0,005 \\
\hline Çalışmayan & $19(52,8)$ & $17(47,2)$ & & \\
\hline \multicolumn{5}{|l|}{ Gelir durumu } \\
\hline İyi & $7(70,0)$ & $3(30,0)$ & & \\
\hline Orta & $33(73,3)$ & $12(26,7)$ & 10,950 & 0,004 \\
\hline Kötü & $0(0,0)$ & $5(100,0)$ & & \\
\hline \multicolumn{5}{|l|}{ Yapılan egzersiz sıklığı } \\
\hline Haftada1-2 kez & $18(78,3)$ & $5(21,7)$ & 10,708 & 0,005 \\
\hline Haftada 3 ve üzeri & $22(66,7)$ & $11(33,3)$ & & \\
\hline
\end{tabular}

Tablo 4. Hasta özelliklerinin egzersiz yapma durumuna etkisi: lojistik regresyon analizi $(n=103)$

\begin{tabular}{|c|c|c|c|c|c|c|}
\hline Değişkenler & B & Wald & p & OR & \multicolumn{2}{|c|}{$\% 95,0 \mathrm{GA}, \mathrm{OR}$} \\
\hline Yaş (60- $\uparrow: 0 / 59-\downarrow: 1)$ & 0,634 & 0,944 & 0,331 & 1,88 & 0,525 & 6,768 \\
\hline Eğitim (Illköğr- $\downarrow: 0 /$ lise- $\uparrow: 1$ ) & 0,842 & 1,828 & 0,176 & 2,32 & 0,685 & 7,866 \\
\hline Gelir (kötü:0/iyi-orta:1) & 3,044 & 9,785 & 0,002 & 20,98 & 3,116 & 141,272 \\
\hline Eklem (kalça-diz:0/bel:1) & 2,063 & 11,175 & 0,001 & 7,87 & 2,348 & 26,374 \\
\hline Bilgi Alma (Alan:0/Almayan:1) & 2,074 & 12,918 & 0,000 & 7,96 & 2,568 & 24,658 \\
\hline (Sabit) & $-4,594$ & 14,813 & 0,000 & 0,01 & & \\
\hline
\end{tabular}




\section{Tartışma}

OA tanısı alan hastaların egzersiz yapma ve egzersizden yarar görme durumlarının tanımlandığı bu çalışma sonucuna göre hastaların yarıdan fazlasının çeşitli düzeylerde egzersiz yaptığı belirlenmiştir. Yapılan diğer çalışmalarda, OA hastalarının toplumun normal egzersiz popülasyonundan daha az egzersiz yaptığı saptanmıştır $(1,10)$. OA hastalarının egzersiz yapmasında öz bakım programlarının (hastaların inançlarının, tutumlarının ve yararlıık algısının) geliştirilmesinin etkili olduğu kanıtlanmıştır (8). Çalışmamızda egzersizin önemi konusunda bilgi alan hastaların bilgi almayan hastalara göre egzersiz yapma olasılığının 7,95 kat daha fazla olduğu saptanmıştır $(p<0,001)$. Hemşirelerden bilgi alan hastaların da diğer sağlık profesyonellerinden bilgi alanlara göre daha fazla egzersiz yaptığı belirlenmiştir $(p<0,005)$. Bu nedenle $O A^{\prime} d a$ öz bakım konusunda planlı hasta eğitimi klinikte sağlık ekibinde eğitici rolüne sahip hemşire tarafından, toplum içinde ise televizyon ve internet vb. kitle iletişim araçları kullanılarak sağlık profesyonelleri tarafından yapılmalıdır. Bu çalışmada istatistiksel olarak anlamlı olmasa da erkeklerin kadınlara göre daha fazla egzersiz yaptıkları belirlenmiştir. Bizim çalışmamızla uyumlu olarak yapılan diğer çalışmalarda da erkeklerin kadınlara göre daha fazla egzersiz yaptıkları görülmüştür $(4,11)$.

Çalışmamızda, egzersiz yapan hastaların yarıdan fazlası yaptıkları egzersizlerden çeşitli oranlarda yarar sağladığını ve yaptıkları egzersizin hastalığa bağlı yaşadıkları ağrı, kilitlenme, yorgunluk ve hareket kısıtlılı̆ı gibi problemleri azalttığını ifade etmiştir. Yapılan benzer çalışmalarda, planlı ev egzersizlerinin OA hastalarında yaşın ilerlemesiyle birlikte daha da artan ağrı, tutukluk, düşme vb. şikayetleri azalttığı belirlenmiştir $(4,7)$. Yapılan bazı çalışmalarda ise bireylerin hastalık algılarını geliştirdiği, diyet, stres yönetimi ve iyi sağlık davranışları uyumunu sağlayarak artrit öz yeterlilik düzeyini ve öz bakım becerilerini artırdığı saptanmıştır (8,12-16). Ayrıca diz OA'sında bir yıl boyunca düzenli ve bireye özgü yapılan ev egzersiz programının bireylerin kullandığı ağrı kesici miktarını azalttığı ve fonksiyonel kapasite artışına neden olarak total eklem replasmanını geciktirebileceği ifade edilmiștir $(17,18)$.

Yaptığımız çalışmada, OA hastalarının yeterli bilgilerinin olmaması, ağrı, etkinliğine inanmama, zaman bulamama ve yalnızlık gibi nedenlerle egzersiz yapmadıkları bulunmuştur. Brawley ve ark. (15) yaptığı çalışmada ise OA hastalarının kötü algılanan sağlık, zaman ve motivasyon eksikliği, ağrı ve yaralanma korkusu gibi nedenlerle egzersiz yapmadıkları belirlenmiştir. Bu konuda yapılan diğer çalışmalarda da OA hastalarının ağıı, şişmanlık, zaman sıkıntısı, uygun yer olmaması, yorucu olması ve gerekli görmeme gibi nedenlerle egzersiz yapmadıkları saptanmıştır (11-14). Bireylere yapılan eğitimlerle; egzersizin yararları, ekleme göre egzersiz, egzersiz süresi ve egzersiz sırasında yaşayacakları sorunlarla baş etme yöntemleri hastaların bireysel özelliklerine göre planlanarak yapılırsa hastaların egzersiz uyumlarını olumlu etkileyebileceği düşünülmektedir.
Gelir düzeyi iyi ve orta olanların kötü olanlara göre 20,98 kat daha fazla egzersiz yapma olasılıklarının olduğu saptanmıştır. Bunda yaşam tarzı, yerleşim yeri gibi kültürel nedenlerin etkin olabileceği düşünülebilir.

Sonuç olarak, egzersizin OA'da sayısız yararı olduğunun bilinmesine ve kabul edilmesine karşın hastaların farkındalığının aynı düzeyde olduğunu söylemek çok güçtür. Günümüz sağlık politikalarında koruyucu sağlık hizmetleri ve bunun için de egzersiz ön plandadır. Bu bağlamda her bölgede çevresel ve kültürel egzersiz engellerini ortadan kaldıracak egzersiz ortamları oluşturulmalı, bireylerin egzersiz yarar algısını geliştirmek için profesyonel sağlık elemanları ve kitle iletişim araçları kullanılarak toplum bilinçlendirilmeli, egzersiz OA hastalarının öz bakımının bir parçası haline getirilmelidir.

Çalışmanın sonuçları sadece bu grup için genellenebilir. Ancak OA hastalarında optimal egzersiz yararlarını belirlemek ve farklı eklemler üzerindeki etkilerini değerlendirmek amacıyla bölgesel eklemlerin sınırlandırıldığı daha çok sayıda hastayı içeren çalışmalara ihtiyaç olduğu kanısındayız.

\section{Çıkar Çatışması:}

Yazarlar herhangi bir çıkar çatışması bildirmemişlerdir.

\section{Kaynaklar}

1. Liikavainio T. Biomechanics of gait and physical function in patients with knee osteoarthritis. In: Kosma VM, Turunen $\mathrm{H}$, editors. Diagnosis and treatment of knee osteoarthritis. $2^{\text {th }}$ ed. Finland: Publication of the Universıty of Eastern: Finland; 2010. p. 15-30.

2. Roddy E, Zhang W, Doherty M, Arden NK, Barlow J, Birrell F, et al. Evidence-based recommendations for the role of exercise in the management of osteoarthritis of the hip or knee the move consensus. Rheumatology 2005;44:67-73.

3. Ünsal S, Özel S, Şahin-Onat Ş, Tiftik T. Osteoartritli yaşlı hastalarda egzersiz engelleri Türk Geriatri Dergisi 2007;10:179-183.

4. Song R, Lee EO, Lam P, Bae Chi. Effects of a sun-style tai chi exercise on arthritic symptoms, motivation and the performance of health behaviours in women with osteoarthritis. Taehan Kanho Hakhoe Chi 2007;37:249-56.

5. Fransen M, Nairn L, Winstanley J, et al. Physical activity for osteoarthritis management: a randomized controlled clinical trial evaluating hydrotherapy or tai chi classes. Arthritis Rheum 2007;157:407-14.

6. Silva LE, Valim V, Pessanha AP, Oliveira LM, Myamoto S, Jones A, et al. Hydrotherapy versus conventional land-based exercise for the management of patients with osteoarthritis of the knee: a randomized clinical trial. Phys Ther 2003;88:12-21.

7. Baczyk G, Samborski P, Pieścikowska J, Kmieciak M, Walkowiak I. Comparison functioning and quality of life of patients with osteoarthritis and rheumatoid arthritis. 2007;52(suppl 1):55-9.

8. Yip YB, Sit JW, Fung KK, Wong DY, Chong SY, Chung LH, et al. Effects of a self-management arthritis programme with an added exercise component for osteoarthritic knee: randomized controlled trial. J Adv Nurs 2007;59:20-8.

9. Yip YB, Sit JW, Fung KK, Wong DY, Chong SY, Chung LH, et al. Impact of an Arthritis Self-Management Programme with an added exercise component for osteoarthritic knee sufferers on improving pain, functional outcomes, and use of health care services: An experimental study. Patient Educ Couns 2007;65:113-21.

10. Jamtvedt G, Dahm KT, Christie A, Moe RH, Haavardsholm E, Holm I, et al. Physical therapy interventions for patients with osteoarthritis of the knee: an overview of systematic reviews. Phys Ther 2008;88:123-36. 
11. Satariano WA, McAuley E. Promoting physical activity among older adults: from ecology to the individual. Am J Prev Med 2003;25(Suppl 2):184-92.

12. Song R, Lee EO, Lam P, Bae SC, et al. Effects of tai chi exercise on pain, balance, muscle strength, and perceived difficulties in physical functioning in older women with osteoarthritis: a randomized clinical trial. J Rheumatol 2003;30:2039-44.

13. Lee HY, Lee KJ. Effects of Tai Chi exercise in elderly with knee osteoarthritis. Taehan Kanho Hakhoe Chi 2008;38:11-8.

14. Petursdottir U, Arnadottir SA, Halldorsdottir S. Facilitators and barriers to exercising among people with osteoarthritis: a phenomenological study. Phys Ther 2010;90:1014-25.
15. Brawley LR, Rejeski W], King AC. Promoting physical activity for older adults: the challenges for changing behavior. Am J Prev Med 2003;25(suppl 3):172-83.

16. Günay M, Şenel Ö, Karacan S, Çolakoğlu F, Cicioğlu I, Atalay Güzel N. Yaşlıların fiziksel performans test skoruna göre fiziksel uygunluk düzeylerinin belirlenmesi. Türk Geriatri Dergisi 2008;11:72-81.

17. Brismee JM, Paige RL, Chyu MC, Kalish R, Roubenoff R, Rones R, et al. Group and home-based tai chi in elderly subjects with knee osteoarthritis: a randomized controlled trial. Clin Rehabil 2007;21:99-111.

18. Wang C, Schmid CH, Hibberd PL, Kalish R, Roubenoff R, Rones R, et al. Tai Chi is effective in treating knee osteoarthritis: a randomized controlled trial. Arthritis Rheum 2009;61:1545-53. 